\title{
Ecological determinants of occupancy and abundance of chinkara (Gazella bennettii) in Yadahalli Wildlife Sanctuary, Karnataka, India
}

\author{
Dinesh Kumar ${ }^{1}$, Avadhoot D. Velankar ${ }^{2,3}$, Nitin Venkatesh Ranga Rao ${ }^{4}$, \\ Honnavalli N. Kumara ${ }^{2, *}$, Partha Sarathi Mishra ${ }^{2,5}$, Prodyut Bhattacharya ${ }^{1}$ and \\ Vijay Mohan Raj ${ }^{6}$
}

${ }^{1}$ Guru Gobind Singh Indraprastha University, Dwarka, Sector 16-C, New Delhi 110078 , India

${ }^{2}$ Sálim Ali Centre for Ornithology and Natural History, Anaikatty Post, Coimbatore 641 108, India

${ }^{3}$ Manipal Academy of Higher Education, Manipal 576 104, India

${ }^{4}$ No. 3001/1-new no. 19, 2nd Main Road, VV Mohalla, Mysuru 570 002, Karnataka, India

${ }^{5}$ Biopsychology Department and Institute of Excellence, University of Mysore, Mysuru 570006 , India

${ }^{6}$ Karnataka Forest Department, Belagavi Forest Circle, Belagavi 590 016, India

Chinkara (Gazella bennettii), the Indian gazelle, is a widespread antelope in the arid and semi-arid regions of the Indian subcontinent; however, the species has been relatively unexplored to the south of its distribution range. In 2016, with indefinite evidence of chinkara presence in Yadahalli Reserved Forest, Karnataka, India, the Forest Department notified the area as a Wildlife Sanctuary (WLS). We conducted a study to explore their possible existence and population status at Yadahalli WLS using a novel approach. We laid 2 sq. $\mathbf{~ k m}$ grid cells in the Yadahalli WLS and divided it into four replicated sub-grids using GPS. We walked the grid cells and recorded the chinkara midden and deployed camera traps for direct detection and individual identity. We recorded site covariates, i.e. tree density, tree diversity, basal area, food tree density, cattle dung, goat and sheep droppings and distance from the boundary, and detection covariates, i.e. trail length. We performed occupancy modelling based on midden recordings using PRESENCE ver. 5.3. Through the effort of 62 grids with four spatial replicates, the detection probability of chinkara was found to be $0.68 \pm 0.03_{\mathrm{SE}}$, and the estimated averaged occupancy was $0.51 \pm 0.37_{\mathrm{SE}}$. The present study reveals a potential population of $\sim 85$ individuals in the Yadahalli WLS, which is the known southernmost population of the species in India. This study establishes the use of novel methods for monitoring of chinkara populations which will help in the development of a conservation action plan for the species and its habitat.

Keywords: Abundance, detection probability, Gazella bennettii, occupancy.

\footnotetext{
*For correspondence. (e-mail: honnavallik@gmail.com)
}

HABITAT composition and herbivore population dynamics have a mutual influence on each other, with ungulates being at the centre. On the one hand, habitat heterogeneity and resource distribution have been found to govern the ungulate populations ${ }^{1-3}$, while on the other, herbivore assemblage has a long-term impact on the surrounding vegetation ${ }^{4}$. Halpin ${ }^{5}$ realized the importance of monitoring and documenting herbivore populations at both local and global scales. However, the methods for monitoring the individuals vary between species and the habitats they occupy. For example, ungulates residing in arid or semiarid landscapes in low density over vast open spaces are usually shy and highly vigilant, which makes it difficult to study them using conventional methods ${ }^{6}$. The Indian gazelle or chinkara (Gazella bennettii) is one such species which, despite being widely distributed in arid and semiarid regions, has been less studied in southern India because of its elusive behaviour and sporadic records.

Among the 19 species of gazelles found in Asia and Africa, chinkara is the only one found in the Indian subcontinent ${ }^{7}$. It is well adapted to, and is widespread in, the arid and semi-arid environs of the region ${ }^{8}$. The extent of its distribution in the subcontinent starts from northcentral Iran on the western side through Pakistan and Afghanistan, till the eastern states of India ${ }^{9}$. Its population is declining considerably in countries like Iran, Pakistan and Afghanistan ${ }^{10}$. In early 1960-70s, chinkara was found abundant in many districts of Balochistan, but during the last decade, its status has been affected severely by anthropogenic disturbances (viz. extensive poaching, livestock grazing) and land-use changes ${ }^{11}$. In India, populations of chinkara have been found to be distributed in 11 states $^{12-15}$. Though the distribution is relatively widespread, the population is declining throughout its distribution range $\mathrm{e}^{16}$. This prompted to accord the highest 
protection (schedule 1) to the species under the Indian Wildlife Protection Act 1972 (ref. 17). The distribution of chinkara has been mostly studied in northern parts of India because of sporadic records from South India. In southern India, chinkara has been found to occur in certain parts of Karnataka ${ }^{12,18}$ and further south in the Coimbatore Forest Division, Tamil $\mathrm{Nadu}^{18}$. Subsequent studies did not record any population to the south of Pennar River, Andhra Pradesh, and a possible local extinction was supposed in large parts of Karnataka and Tamil Nadu ${ }^{12,19}$. Thus knowledge about chinkara has been scanty. Although the distribution map of chinkara by Rahmani $^{13}$ depicts a possible historical range in Karnataka, the range map in the IUCN website does not include Karnataka. However recently, Desai ${ }^{20}$ reported the occurrence of chinkara from the Yadahalli Reserved Forest in Bagalkot district, which lies in the semi-arid region of Karnataka; this led to the reserved forest being notified as a Wildlife Sanctuary (WLS) in 2016. This was the first report in the last four to five decades about a possible occurrence of chinkara.

We conducted the present study to confirm the occurrence of chinkara based on the habitat covariates to further our understanding of the species at Yadahalli WLS. We employed methods suitable for this shy and elusive species in its natural habitat. Here, we report findings of the study conducted to assess the conservation status of chinkara in Yadahalli WLS using a methodology which could be standardized for further studies on the species throughout its distribution range.

\section{Materials and methods}

\section{Study area}

The Yadahalli WLS is located in northern Karnataka between $16^{\circ} 18^{\prime} 00^{\prime \prime}-16^{\circ} 23^{\prime} 47^{\prime \prime} \mathrm{N}$ lat. and $75^{\circ} 24^{\prime} 00^{\prime \prime}$ $75^{\circ} 37^{\prime} 43^{\prime \prime} \mathrm{E}$ long. (Figure 1). The sanctuary is spread over $96 \mathrm{sq} . \mathrm{km}$. The temperature ranges between $14^{\circ} \mathrm{C}$ in December-January and $38^{\circ} \mathrm{C}$ in April-May and average annual rainfall is $580 \mathrm{~mm}$ (ref. 21). The vegetation of the study area includes southern dry mixed deciduous forest, southern thorn forest, southern thorn scrub, southern euphorbia scrub, babul forest and inundation babul forests $^{22}$. The flora mainly consists of Chloroxylon swietenia, Albizia amara, Wrightia tinctoria, Anogeissus latifolia, Acacia nilotica, Mundulea suberosa and Diospyros melanoxylon as the dominant tree species ${ }^{21}$.

\section{Field methods}

The number of middens and the quantity of faecal deposits in an area indicate the occurrence and intensity of use by a species in that area. During our reconnaissance survey, we did not observe chinkara which is in agree- ment to earlier reports from the study site ${ }^{20}$. Hence, we opted for the occupancy framework by sampling middens and photographic captures of chinkara using camera trap technique, which is a reliable source for assessment of population status of shy and elusive animals ${ }^{6}$. A 'midden' is a site where chinkara defecate frequently ${ }^{13}$. Detecting middens further avoided the confusion of detection with livestock, as neither goats nor sheep defecate at a common site. The Yadahalli WLS boundary was overlaid with 2 sq. km grid study on the 'geographical information system' platform using QGIS for camera trapping. The 2 sq. $\mathrm{km}$ grid size was chosen based on known home range of the species with similar forest structure, which was estimated to be $\sim 2 \mathrm{~km}^{2}$ (ref. 16). Each $2 \mathrm{sq}$. $\mathrm{km}$ grid was further divided into four sub-grids, which were used to sample middens. The Yadahalli WLS spanned over 65 grid cells, of which 36 were used for camera-trapping. Due to loss of camera traps during the initial phase, few peripheral grids close to human settlements were not sampled. Midden survey was conducted in 62 grids (Figure 1). The fieldwork was carried out during the dry season from February to May 2016.

Midden survey: We uploaded the shapefile of the grid cells to a handheld GPS (GARMINeTrex) using DNR Garmin application. Using this, the grid cells were located on the field. Once a grid cell was located, we selected the existing trail in the grid or randomly decided the walking path in order to cover the entire grid cell. We turned the track mode on to record the path in GPS and walked slowly by searching for middens. We sampled 62 grids and during the walk, we recorded the geocoordinates for all detections of middens using a handheld GPS receiver (Figure 1). We also determined the average visibility as it is considered to be one of the influencing factors for midden site selection for chinkara ${ }^{23}$.

Camera-trapping: We used 30 'trail cameras' (HCO Scout Guard) and deployed five camera traps in each grid cell for five days. We placed one camera trap at the centre of each sub-grid and one at the centre of the main grid. The geo-coordinates for each camera trap location were recorded using a handheld GPS receiver. Apart from GPS readings of camera traps, data on time and date of camera deployment and removal, elevation of the area and terrain type were recorded. Camera traps were checked each morning to confirm the presence and assure proper functioning of the cameras. Camera traps were removed on the sixth day, and images were downloaded and organized according to grids and sub-grids.

Vegetation structure and anthropogenic variables: To assess the environmental and anthropogenic variables, we laid $10 \times 10 \mathrm{~m}$ quadrats on a diagonal line within a grid cell. The quadrats were laid for $5 \mathrm{~m}$ either side of the diagonal line. The minimum distance between the two 


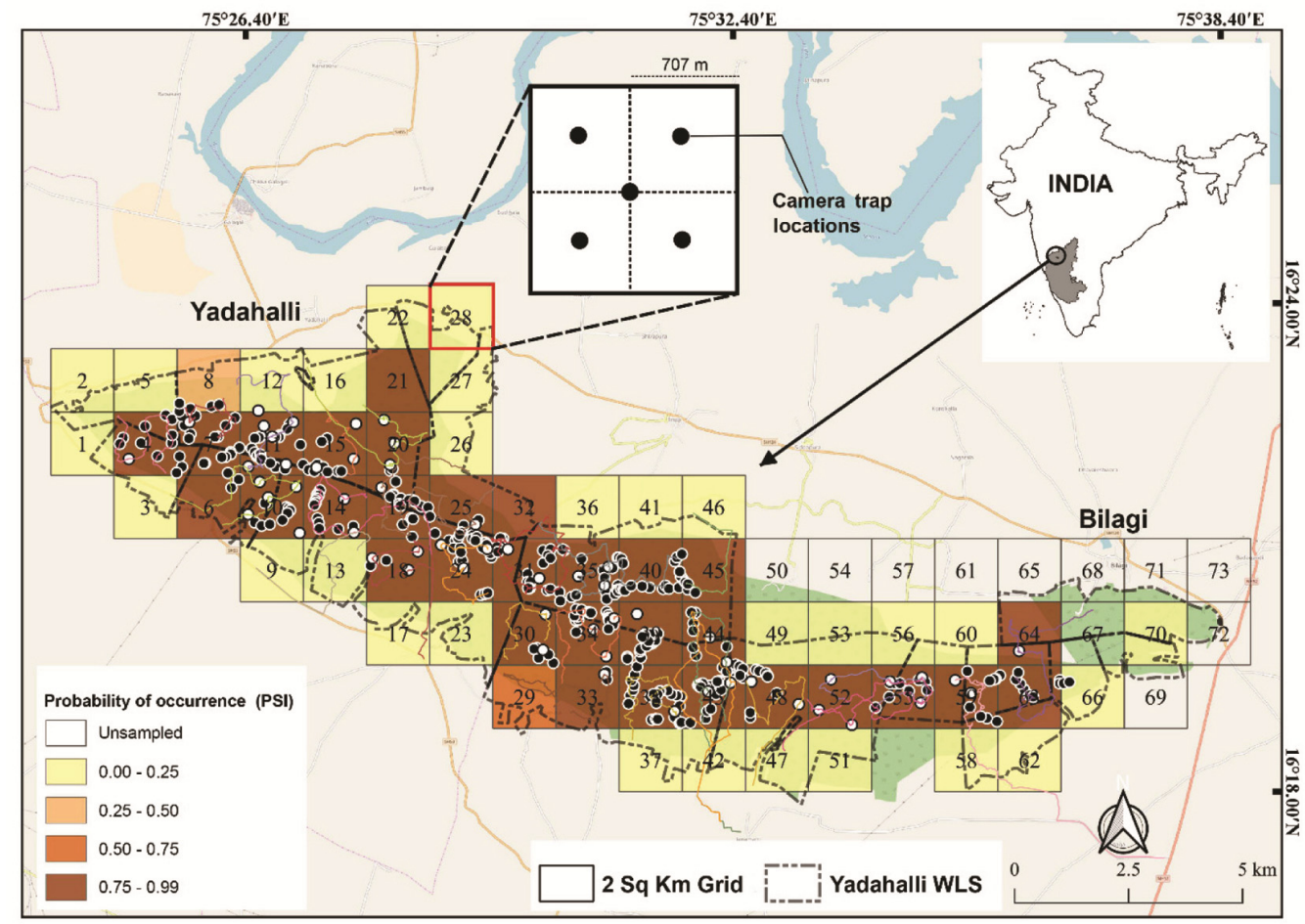

Figure 1. Map depicting location of capture, midden and probability of occurrence in each 2 sq. $\mathrm{km}$ grid at Yadahalli Wildlife Sanctuary, Karnataka, India.

Table 1. Predicted species response to each covariate based on our a priori hypothesis for chinkara

\begin{tabular}{lcc}
\hline & \multicolumn{2}{c}{ Midden } \\
\cline { 2 - 3 } Covariates & $\psi$ & $P$ \\
\hline TR & + & - \\
FDTR & + & 0 \\
BA & + & 0 \\
DIVE & + & 0 \\
CATT & - & 0 \\
GOAT & - & 0 \\
DIST & + & 0 \\
KM & + & + \\
\hline
\end{tabular}

TR, Tree density; FDTR, Food tree density; BA, Basal area; DIVE, Plant species diversity; CATT, Cattle dung density; GOAT, Goat drooping density; DIST, Distance from the boundary; KM, Trail length. '+' signifies a positive effect on the response variable, '-' signifies a negative effect and ' 0 ' signifies that the covariate does not affect the response variable. '-' Not applicable. $\psi$ is the probability of occurrence and $P$ is the species detection probability.

quadrats was $400 \mathrm{~m}$ across the diagonal line. Plant species having minimum $0.10 \mathrm{~m}$ girth were considered as trees, and height of the trees was measured using a hypsometer. The girth at breast height $(\mathrm{GBH})$ for each stem more than $0.10 \mathrm{~m}$ was measured. Number and area covered by bushes in each quadrat were recorded. Taxonomic identification of the species was done follow- ing Flora of Karnataka by Saldanha ${ }^{24}$. We also recorded the count of dung piles of livestock in quadrats. On the GIS platform, we measured the distance of the grid corner to the forest boundary and the nearest village.

\section{Statistical analysis}

A priori hypothesis: Considering the biology of chinkara and habitat conditions, an a priori hypothesis was established to determine the parameters that might influence their detection and occupancy in the grid cells (Table 1). We categorized site-level covariates as ecological variables: tree density (TR), tree diversity (DIVE), basal area (BA) and food tree density (FDTR); anthropological variables: cattle dung (CATT), goat and sheep droppings (GOAT) and distance from the boundary (DIST). We used trail length (KM) as a covariate for detection probability.

Independent variables: Using plant data from each quadrat we calculated TR and FDTR by dividing the total number of individuals/area sampled $\times 10,000$ and BA using the formula $(\mathrm{GBH})^{2} / 4 \pi$. The plant species diversity (DIVE) was represented by Shannon-Wiener's index using the formula

$$
H^{\prime}=-\sum\left(n_{i} / N\right) \ln \left(n_{i} / N\right),
$$

for each grid cell. We listed five species as the most important food species for this study area based on the 
RESEARCH ARTICLES

Table 2. Detection probabilities for chinkara midden

\begin{tabular}{lcccccc}
\hline Model & $\hat{p} \pm \mathrm{SE}$ & $\mathrm{AIC}_{\mathrm{c}}$ & $\mathrm{AIC}_{\mathrm{c}}$ & $w_{i}$ & $K$ & Naïve occupancy \\
\hline$\psi(),. p(\mathrm{KM})$ & $0.68 \pm 0.03$ & 225.20 & 0.00 & 0.90 & 3 & 0.44 \\
$\psi(),. p()$. & $0.70 \pm 0.04$ & 229.58 & 4.38 & 0.10 & 2 & \\
\hline
\end{tabular}

$\hat{p}$, Estimated species detection probability; $\mathrm{AIC}_{\mathrm{c}}$, Akaike information criterion corrected for small-sample bias; $\Delta \mathrm{AIC}_{\mathrm{c}}$, Difference in $\mathrm{AIC}_{\mathrm{c}}$ values between each model and the model with the lowest $\mathrm{AIC}_{\mathrm{c}}, w_{i}, \mathrm{AIC}_{\mathrm{c}}$ model weight; K, Number of parameters estimated by the model and KM, Trail length.

Table 3. Model for occupancy of chinkara using midden

\begin{tabular}{lcccccc}
\hline Model & $\hat{\psi}$ & $S \hat{E}$ & $\mathrm{AIC}_{\mathrm{c}}$ & $\Delta \mathrm{AIC}_{\mathrm{c}}$ & $w_{i}$ & $K$ \\
\hline$\psi(\mathrm{BA}+\mathrm{CATT}+\mathrm{DIST}), p(\mathrm{KM})$ & 0.5161 & 0.3710 & 170.95 & 0 & 0.6519 & 4 \\
$\psi(\mathrm{BA}+\mathrm{CATT}), p(\mathrm{KM})$ & 0.5125 & 0.0522 & 173.28 & 2.33 & 0.2033 & 4 \\
$\psi(\mathrm{BA}), p(\mathrm{KM})$ & 0.5280 & 0.0347 & 173.96 & 3.01 & 0.1447 & 2 \\
$\psi(\mathrm{DIST}), p(\mathrm{KM})$ & 0.4821 & 0.0486 & 210.33 & 39.38 & 0 & 2 \\
$\psi(\mathrm{DIVE}), p(\mathrm{KM})$ & 0.5082 & 0.0471 & 212.76 & 41.81 & 0 & 2 \\
$\psi(\mathrm{CATT}), p(\mathrm{KM})$ & 0.5087 & 0.0483 & 213.02 & 42.07 & 0 & 2 \\
$\psi(\mathrm{GOAT}), p(\mathrm{KM})$ & 0.5175 & 0.0502 & 217.12 & 46.17 & 0 & 2 \\
$\psi(\mathrm{FDTR}), p(\mathrm{KM})$ & 0.4995 & 0.0479 & 224.32 & 53.37 & 0 & 2 \\
$\psi(\mathrm{TR}), p(\mathrm{KM})$ & 0.4993 & 0.0479 & 224.32 & 53.37 & 0 & 2 \\
$\psi(),. p(\mathrm{KM})$ & 0.4744 & 0.0643 & 225.20 & 54.25 & 0 & 2 \\
\hline
\end{tabular}

$\hat{\psi}$, Estimated occupancy parameter; $S \hat{E}$, Associated standard error.

literature and using our field observations to calculate FDTR. DIST, CATT and GOAT were considered as independent variables which may affect habitat selection of chinkara. We considered the variation in trail length to be the influencing factor for detection rate of middens.

Occupancy and abundance modelling: The detection of middens in each sub-grid was considered as a spatial replicate, and the capture of chinkara in each $24 \mathrm{~h}$ cycle for five days was considered as a temporal replicate. A binary presence/absence matrix of detection history was constructed for middens and captures by camera traps. The detection probability, occupancy and abundance were computed using PRESENCE software v.5.3 (USGS, USA). Assuming the population was closed during sampling, single-season occupancy modelling was used for the estimation of detection probability $(P)$ and proportion of sites occupied $(\psi)$.

Models were first developed to check whether the site covariates affect the detection probability. A null model was developed keeping the detection probability constant $p(\cdot)$ for each site covariate. Then the model was compared with other models (site-covariates) to estimate the detection probability. The models were ranked according to the $\triangle$ AIC (Akaike information criterion) value. The lowest $\triangle \mathrm{AIC}$ value was ranked highest ${ }^{25}$, and the average of all the models was calculated to estimate the final occupancy. Generalized linear modelling (GLM) was carried out for the estimation of determinants for the relative abundance of chinkara middens. The modelling was performed using R v 3.5.1 software ${ }^{26}$.

We estimated the abundance of chinkara for the sampled area using Royle and Nichols model ${ }^{27}$ in
PRESENCE v5.3 (USGS, USA) using capture data from camera traps. Further, using the estimated abundance in the sampled area, we extrapolated to other areas occupied by the chinkara using occupancy models deduced from middens. Captured photographs were examined for identification of individuals, and differentiating between males and females based on the differences in horn size and annuli pattern. The shape and annuli number of horns, and some morphological characters like marks on the body and wound scars, were used to identify the individuals. The sex ratio was computed using data on age-sex of the individuals and their identity.

\section{Results}

A total of $217.73 \mathrm{~km}$ was covered by walking in the 62 grids, during which we recorded the middens of chinkara in 30 grids. We recorded a total of 357 middens of chinkara in 60 sq. $\mathrm{km}$ (30 grid cells). The average visibility range around a midden was 3359 sq. m, which ranged between 198 and 20,700 sq. $\mathrm{m}^{2}$. Largely, the middens were placed at 'relatively open area' within thick vegetation.

The analysis from 62 sites with four sampling occasions provided an estimated detection probability $(p)$ of $0.68 \pm 0.03$ for the middens (Table 2). The distance walked (KM) in each sub-grid influenced the detection probability of middens, i.e. $w_{i}=0.90$. Subsequent models were run with $\mathrm{KM}$ as a function of $p$. The estimated naïve occupancy was 0.40 . The estimated occupancy for middens was $\psi(),. p()=.0.51 \pm 0.37$. Since $w_{i}$ of the top model was more than 0.5 , we did not sum the $\mathrm{AIC}_{\mathrm{c}}$ 
wt. and considered the top-ranking model as a predictor (Table 3). The occupancy of chinkara was positively correlated with BA: $\beta=8.93 \pm 5.15$ and DIST: $\beta=2.22 \pm$ 1.59, while CATT had a negative influence ' $\beta=$ $-2.57 \pm 2.15^{\prime}$ (Table 4 ). The site occupancy estimates were classified as low $(\hat{\psi}=0.00-0.25)$, medium $(\hat{\psi}=0.25-0.50)$, high $(\hat{\psi}=0.50-0.74)$, very high $(\hat{\psi}=$ 0.74-0.99), and mapped, which shows that 33 out of 62 grids have a high probability, while 29 grids show relatively less probability of occupancy of chinkara in the study site (Figure 1).

GLM revealed BA as a significant determinant for relative abundance of chinkara. A model involving only BA was found to be the most suitable when compared with combinations of other covariates $\left(\mathrm{AIC}_{\mathrm{c}}=163.14\right.$; Table $5)$. Areas with high abundance of chinkara correspond to high BA $(\beta=0.79 \pm 0.29)$.

A total of 83 animals were identified in $72 \mathrm{sq} . \mathrm{km}$ of the area with a mean herd size of $1.20 \pm 0.51_{\mathrm{SD}}$ individuals, which varied between 1 and 4 . According to the Royle and Nichols model ${ }^{27} \quad\left(r=0.29 \pm 0.06_{\mathrm{SD}}\right.$ and $\left.\lambda=1.50 \pm 0.39_{\mathrm{SD}}\right)$, abundance in the sampled area was estimated to be 54.00. The individuals in each sampled grid were not detected in the neighbouring grids, except two adult males which were detected at the border of the adjoining grids. We multiplied site abundance with the mean herd size, which provided an estimate of 64 animals in $72 \mathrm{sq} . \mathrm{km}$ area. We extrapolated this estimate to other unsampled grids to approximate the possible population size in Yadahalli WLS, which was 85 animals in 96 sq. $\mathrm{km}$ of the sanctuary.

\section{Discussion}

Many of the antelopes have evolved and adapted for the plains, but also live in open scrub forests and productive landscapes. Chinkara is one among them known to extend from the Thar Desert to open scrub forests. Various studies have been conducted in different habitat types to estimate their density, like road surveys in desert areas and productive fields in Rajasthan ${ }^{13,14,28,29}$; line transects in the forested areas or protected areas with forest cover in Kutch and Gir in Gujarat, and Ranthambore Tiger Reserve in Rajasthan ${ }^{30-32}$, but there has been a lack of consistency in the results. Estimates using road surveys for different studies in Rajasthan varied highly (Table 6). Except in the Gogelao Enclosure in Nagaur ${ }^{33}$ and Ranthambore Tiger Reserve ${ }^{30}$, the estimated density of

Table 4. Covariates influencing chinkara occupancy on basis of $\beta$-coefficients and standard error

\begin{tabular}{lcc}
\hline Covariate & $\beta$-coefficient & $S \hat{E}$ \\
\hline Basal area (BA) & 8.93 & 5.15 \\
Distance (DIST) & 2.22 & 1.59 \\
Cattle (CATT) & -2.57 & 2.15 \\
\hline
\end{tabular}

chinkara for all the sites was less than 3 individuals/ sq. $\mathrm{km}$, including the Yadahalli WLS. The present population density estimate indicates the existence of a sizable population in the Yadahalli WLS.

Results confirm the home range size of a herd or an individual chinkara in Yadahalli WLS to less than or equal to $2 \mathrm{sq} . \mathrm{km}$, as the individuals were not found outside the border of the grids or neighboring grids. This is in agreement with Dookia ${ }^{16}$, who reported 2 sq. $\mathrm{km}$ of home range size in scrub forests of Rajasthan. Further, the Royle and Nichols model ${ }^{27}$ deduced a density of $0.88 / \mathrm{sq}$. km, which corresponds to minimum population size derived from total count made using the photocapture technique $(0.86-0.99 / \mathrm{sq}$. $\mathrm{km})$.

Chinkara live in small herds of about 2-3 individuals, with mean herd size varying between 1.2 in Yadahalli, Karnataka and 2.60 in Ranthambore, Rajasthan ${ }^{34}$ and Kachchh, Gujarat ${ }^{32}$. However, a mean herd size of 5.01 was reported in Mayureshwara WLS, which is a small protected area notified to protect chinkara ${ }^{35}$. Probably, the high protection and limitations of the area have positively influenced the herd size in Mayureshwara WLS. Although the herd size in the present study is comparatively smaller, our estimates are highly reliable due to the use of infrared cameras used for camera-trapping technique.

The sex ratio was biased towards females in most of the range (Table 6); however, it was negative in Ranthambore $(1: 0.83)$ and Yadahalli (1:0.83), while adult female to fawn ratio did not differ between the sites $(0.15-0.35)$. This requires further exploration to understand the population dynamics and survival rate of chinkara under different ecological conditions.

In Yadahalli WLS, the occupancy and abundance of chinkara were determined by the BA. However, the record of midden sites shows that they choose small, open areas which are the centre of their activities. As they feed on leaves from many shrubs and small trees, they were found more in the higher basal area, and further, they choose small, open areas within good forest cover. Thus, basal area is an important covariate which positively influences the occupancy and abundance of chinkara in Yadahalli WLS.

\section{Conclusion}

This study establishes the presence of chinkara in the southern extremity of its distribution. Being an arid environment species with $\sim 2 \mathrm{sq} . \mathrm{km}$ home range, the chinkara can have a healthy population even at low densities, making its monitoring difficult. This study demonstrates methodologies which can be employed to survey low-density populations of an elusive species through the use of camera traps and survey of middens. Further, these methods can also be employed for periodical monitoring 
RESEARCH ARTICLES

Table 5. Summary of the model selection procedure for covariates influencing relative abundance of chinkara with $R^{2}$ and corresponding $P$ values, $\beta$-coefficients and associated standard errors

\begin{tabular}{lccccccc}
\hline Covariates & $R^{2}$ & $P$ & $\mathrm{AIC}_{\mathrm{c}}$ & $\Delta \mathrm{AIC}_{\mathrm{c}}$ & $K$ & $\beta$-coefficient & $S \hat{E}$ \\
\hline BA & 0.1780 & 0.000 & 163.14 & 0 & 1 & 0.7914 & 0.2917 \\
BA + DIST & 0.1781 & 1.600 & 165.13 & 1.99 & 2 & 0.4085 & 0.3574 \\
BA + DIST + CATT & 0.1840 & 4.391 & 166.87 & 3.73 & 3 & 0.2462 & 0.2483 \\
TR & 0.0797 & 0.000 & 167.20 & 4.06 & 1 & 0.0028 & 0.0017 \\
DIVE & 0.0482 & 0.002 & 168.41 & 5.27 & 1 & 2.4550 & 1.8720 \\
CATT & 0.0383 & 0.005 & 168.79 & 5.65 & 1 & -0.0046 & 0.0040 \\
FDTR & 0.0098 & 0.160 & 169.84 & 6.70 & 1 & 0.0016 & 0.0029 \\
DIST & 0.0072 & 0.229 & 169.93 & 6.79 & 1 & 0.2188 & 0.4414 \\
GOAT & 0.0006 & 0.745 & 170.17 & 7.03 & 1 & 0.0006 & 0.0045 \\
BA + DIST + CATT+ GOAT + TR & 0.2453 & 1.856 & 172.06 & 8.92 & 7 & 0.1769 & 0.5569 \\
$\quad$ FDTR + DIVE & & & & & & & \\
\hline
\end{tabular}

Table 6. Density and other variables of chinkara in other study sites

\begin{tabular}{|c|c|c|c|c|c|c|}
\hline Location & Method & $\begin{array}{l}\text { Density } \\
\left(\mathrm{km}^{-2}\right)\end{array}$ & $\begin{array}{l}\text { Herd } \\
\text { size }\end{array}$ & $\begin{array}{l}\text { Ratio } \\
(\mathrm{M}: \mathrm{F})\end{array}$ & $\begin{array}{c}\text { Ratio } \\
(\mathrm{F}: \text { fawn })\end{array}$ & Reference \\
\hline Thar Desert, Rajasthan & Road survey & 0.74 & $1-3$ & $1: 1.3$ & - & 12 \\
\hline Thar Desert, Rajasthan & Road survey & 0.74 & - & - & - & 28 \\
\hline Thar Desert, Rajasthan & Road survey & 0.89 & - & - & - & 29 \\
\hline Thar Desert, Rajasthan & Road survey & 1.09 & - & - & - & 14 \\
\hline Thar Desert, Rajasthan & Road survey & 0.76 & - & $1: 2.20$ & - & 14 \\
\hline $\begin{array}{l}\text { Mayureshwara Wildlife Sanctuary, } \\
\text { Pune }\end{array}$ & Road survey & - & 5.01 & - & - & 35 \\
\hline $\begin{array}{l}\text { Gogelao Enclosure, Nagaur, } \\
\text { Rajasthan }\end{array}$ & Line transect & $\begin{array}{l}48.4 \\
49.6\end{array}$ & - & $1: 1.45$ & - & 33 \\
\hline Kachchh, Gujarat & Line transect & 0.005 & 2.55 & $1: 1.46$ & - & 32 \\
\hline Gir, Gujarat & Road strip count/line transect & 1.20 & 2.22 & & - & 31 \\
\hline $\begin{array}{l}\text { Narayan Sarovar Chinkara Sanctuary, } \\
\text { Gujarat }\end{array}$ & - & 1.25 & - & $1: 1.35$ & - & 36 \\
\hline $\begin{array}{l}\text { Narayan Sarovar Chinkara Sanctuary } \\
\text { Gujarat }\end{array}$ & - & 2.89 & - & & $1: 0.15$ & 37 \\
\hline Ranthambore, Rajasthan & Line transect & 5.60 & $2.5-2.6$ & $1: 0.83$ & $1: 0.35$ & 30 \\
\hline Cholistan Game Reserve, Pakistan & - & 0.16 & - & $1: 1.75$ & - & 38 \\
\hline Yadahalli WLS, Karnataka & Photo-capture & 0.88 & 1.20 & $1: 0.83$ & $1: 0.24$ & Present study \\
\hline
\end{tabular}

of chinkara and other antelopes. As ungulate densities and vegetation are interdependent, their period monitoring will help understand the health of the ecosystem and establish management practices.

1. Illius, A. W. and O'Connor, T. G., Resource heterogeneity and ungulate population dynamics. Oikos, 2000, 89, 283-294.

2. Owen-Smith, N. and Mills, M. G. L., Manifold interactive influences on the population dynamics of a multispecies ungulate assemblage. Ecol. Monogr., 2006, 76, 73-92.

3. Mueller, T., Olson, K. A., Fuller, T. K., Schaller, G. B., Murray, M. G. and Leimgruber, P., In search of forage: predicting dynamic habitats of Mongolian gazelles using satellite-based estimates of vegetation productivity. J. Appl. Ecol., 2008, 45, 649-658.

4. Nuttle, T., Ristau, T. E. and Royo, A. A., Long-term biological legacies of herbivore density in a landscape-scale experiment: forest understoreys reflect past deer density treatments for at least 20 years. J. Ecol., 2014, 102, 221-228.

5. Halpin, P. N., Global climate change and natural-area protection: management responses and research directions. Ecol. Appl., 1997, 3, 828-843.
6. Gil-Sánchez, J. M. et al., Evaluating methods for surveying the endangered Cuvier's gazelle Gazella cuvieri in arid landscapes. Oryx, 2017, 51, 648-655.

7. Groves, C. P., An introduction to the gazelles. Chinkara, 1985, 1, 4-10.

8. Prakash, I., Ecology of artiodactyles in the Thar Desert: their conservation in the desert biosphere reserve. In Mammals in the Palaearctic Desert: Status and Trends in the Sahara-Gobian region (eds McNeely, J. A. and Neronov, V. M.), Russian Academy of Science, Moscow, 1990, pp. 243-250.

9. IUCN SSC Antelope Specialist Group, Gazella bennettii. The IUCN Red List of Threatened Species 2017: e.T8978A50187762.http://dx.doi.org/10.2305/IUCN.UK.20172.RLTS.T8978A50187762.en, downloaded on 19 May 2018.

10. Mallon, D. P., Kingswood, S. C. and East, R., In Antelopes Part 4: North Africa, the Middle East, and Asia, Global Survey and Regional Action Plans (ed. Habibi, K.), Iran. IUCN, Gland, Switzerland, 2001, pp. 119-122.

11. Virk, A. T., Management plan for wild ungulates in Balochistan, Pakistan, University of Montana, USA, 1991.

12. Rahmani, A. R., Distribution of the Indian gazelle or chinkara Gazellabennetti (Sykes) in India. Mammalia, 1990, 54, 605-620. 


\section{RESEARCH ARTICLES}

13. Rahmani, A. R., Distribution, density, group size and conservation of the Indian gazelle or chinkara Gazella bennetti (Sykes 1831) in Rajasthan, India. Biol. Conserv., 1990, 51, 177-189.

14. Dookia, S., Rawat, M., Jakher, G. R. and Dookia, B. R., Status of the Indian gazelle (Gazella bennettii Sykes, 1831) in the Thar Desert of Rajasthan, India. In Faunal Ecology and Conservation of the Great Indian Desert (eds Sivaperuman, C. et al.), Springer, Berlin, Germany, 2009, pp. 193-207.

15. Ben, V. C., Kulkarni, D. K. and Bhagat, R. B., Habitat conservation of chinkara (Gazelle gazelle) in protected areas of Maharashtra and Gujarat. Biosci. Discov., 2013, 4, 139-142.

16. Dookia, S., Conservation of Indian gazelle or chinkara through community support in Thar Desert of Rajasthan, India. Report submitted to The Rufford Small Grants, UK, 2009.

17. Anon., The Indian Wildlife (Protection) Act, Government of India, 1972.

18. Pythian-Adams, E. G., Jungle memories. Part IX - Antelopes and deer. J. Bombay Nat. Hist. Soc., 1951, 50, 1-19.

19. Seshadri, B., The Twilight of India's Wild Life, John Baker, London, UK, 1969, p. 12

20. Desai, M. R., Chronicling the chinkara conservation, 2015; http://jlrexplore.com/explore/focus/chinkara-conservation (retrieved on 30 December 2018).

21. Forest Action Plan, Bagalkot Forest Division, Bagalkot, Karnataka 2012.

22. Champion, H. G. and Seth, S. K., Revised Survey of Forest Types of India, Government of India, New Delhi, 1968.

23. Sharma, K., Rahmani, A. R. and Chundawat, R. S., Natural history observations of the four-horned antelope Tetracerus quadricornis. J. Bombay Nat. Hist. Soc., 2009, 106, 72-82.

24. Saldanha, C. J., Flora of Karnataka, Vol. II, Oxford and IBH Publishers, 1996, p. 304.

25. Burnham, K. P. and Anderson, D. R., Practical use of the information - theoretic approach. In Model Selection and Inference (eds Burnham, K. P. and Anderson, D. R.), Springer, New York, USA, 1998, pp. $75-117$

26. Team, R. and Core, R., R: A language and environment for statistical computing, 2013, 201.

27. Royle, J. A. and Nichols, J. D., Estimating abundance from repeated presence-absence data or point counts. Ecology, 2003, 84, 777-790.

28. Rahmani, A. R., Wildlife in the Thar, Worldwide Fund for NatureIndia, New Delhi, 1997, p. 100

29. Kankane, P. L., Status survey of chinkara and desert cat in Rajasthan. Rec. Zool. Surv. India Occeas Pap., 2000, 179, 1-71.
30. Bagchi, S., Goyal, S. P. and Shankar, K., Social organisation and population structure of ungulates in a dry tropical forest in western India (Mammalia, Artiodactyla). Mammalia, 2008, 72, 44-49.

31. Khan, J. A., Chellam, R., Rodgers, W. A. and Johnsingh, A. J. T., Ungulate densities and biomass in the tropical dry deciduous forests of Gir, Gujarat, India. J. Trop. Ecol., 1996, 12, 149-162.

32. Gajera, N., Mahato, A. K. R. and Kumar, V. V., Habitat preference and social composition of antelopes in arid region of Kachchh, Gujarat, India. Asian J. Conserv. Biol., 2014, 3, 164 169.

33. Jakher, G. R., Dookia, S. and Dookia, B. R., Herd composition and population dynamics of Gazella bennettii (Skyes, 1831) in Gogelao Enclosure (Nagaur), Rajasthan. Zoos Print J., 2002, 17, 936-938.

34. Bagchi, S., Goyal, S. P. and Sankar, K., Herbivore density and biomass in a semi-arid tropical dry deciduous forest of western India. J. Trop. Ecol., 2004, 20, 475-478.

35. Gaikwad, M. C. and Narwade, S. S., The status of chinkara Gazella bennettii (Mammalia: Cetartiodactyla: Bovidae) at Mayureshwara Wildlife Sanctuary, Supe, Baramati, Pune and a note on its current distribution in the southwestern region of the Deccan Plateau of Maharashtra, India. J. Threat. Taxa, 2016, 8, 8590-8595.

36. Chhabra, I. K., Status Paper on Narayan Sarovar chinkara Sanctuary. Gujarat Forest Department, Kachchh West Division, Gujarat, 1989.

37. GEER, GUIDE (2001) Ecological status of Narayan Sarovar Wildlife Sanctuary with respect to flora, fauna, and dependent communities: a management perspective. Bhuj, Gujarat, 2001.

38. Arshad, M. I. and Gill, A. H., Population status of Indian chinkara in Cholistan Game Reserve, Punjab, Pakistan. Russ. J. Ecol., 2010, 41, 524-530.

ACKNOWLEDGEMENTS. This study was carried out with financial support from the Karnataka Forest Department. We thank the Principal Chief Conservator of Forest, Karnataka and staff of the Yadahalli WLS for assistance. We also thank M. R. Desai (Yadahalli), for initiating this study and for his constant support, and the Director, Sálim Ali Centre for Ornithology and Natural History, Coimbatore for providing the facilities and encouragement throughout the study period.

Received 1 January 2019; revised accepted 30 September 2019

doi: $10.18520 / \mathrm{cs} / \mathrm{v} 118 / \mathrm{i} 2 / 264-270$ 